\title{
Violência Doméstica e Autocontrole com Consequências Aversivas Atrasadas e Prováveis
}

\author{
Cristiano Coelho ${ }^{1}$ \\ Pontifícia Universidade Católica de Goiás, Goiânia-GO, Brasil \\ Renata Limongi França Coelho Silva \\ Instituto Integrado de Saúde e Comportamento, Catalão-GO, Brasil
}

\section{RESUMO}

Visando avaliar a relação entre histórico de violência doméstica e autocontrole, 53 homens e 82 mulheres realizaram escolhas em contextos hipotéticos de violência doméstica e de perda de dinheiro, em um programa de computador. No contexto de violência, escolheram entre prisão, para os homens, imediata por um ou seis meses, e prisão após um ano ou com $50 \%$ de chance. Com dinheiro, escolheram entre perder R $\$ 100,00$ imediatamente e perdas com 50\% de chance ou após um ano. O tempo de prisão e a perda de dinheiro atrasados/ prováveis eram aumentados para avaliar equivalência com as prisões e perdas imediatas. Mulheres e homens sem histórico indicaram menores tempos de prisão atrasados que os homens com histórico. Com dinheiro, os homens com histórico preferiram perdas atrasadas maiores que as mulheres, mas o contrário com probabilidade. Esses dados são compatíveis com maior evitação de consequências imediatas aversivas pelos homens com histórico, um indicativo de maior nível de impulsividade.

Palavras-chave: violência doméstica; desconto intertemporal; impulsividade.

\section{ABSTRACT - Domestic violence and self-control with delayed and probabilistic aversive consequences}

To assess the relationship between historic of domestic violence and self-control, 53 men and 82 women made choices in hypothetical contexts of domestic violence and money loss using a computer program. In the context of violence, they chose between immediate detention for men for one or six months and detention after one year or with a $50 \%$ chance. With money they chose between losing $\$ 100$ immediately and losses with a 50\% chance or after one year. Delayed/probable detention duration and loss of money were increased to assess equivalence with immediate detentions and losses. Women and men without historic violence indicated shorter delayed detention durations than men with historic violence. With money, men with historic violence preferred higher losses than the women, however, presented the opposite regarding probability. These data are compatible with greater avoidance of immediate aversive consequences by men with a history of violence, indicative of a higher level of impulsivity.

Keywords: domestic violence; intertemporal discounting; impulsivity.

RESUMEN - Violencia doméstica y autocontrol con consecuencias aversivas retrasadas y probables

Con el intuito de evaluar la relación entre el historial de violencia doméstica y el autocontrol, 53 hombres y 82 mujeres tomaron decisiones en contextos hipotéticos de violencia doméstica y pérdida de dinero en un programa de ordenador. En el contexto de violencia para hombres, eligieron entre prisión inmediata por uno o seis meses y prisión pasado un año o $50 \%$ de probabilidad. Con dinero, eligieron entre perder $\mathrm{R} \$ 100,00$ de inmediato y pérdidas con una probabilidad del $50 \%$ o después de un año. El tiempo de prisión y la pérdida de dinero retrasado/probable se incrementaron para evaluar la equivalencia con las prisiones y las pérdidas inmediatas. Las mujeres y los hombres sin antecedentes indicaron tiempos de prisión más cortos que los hombres con antecedentes. Con el dinero, los hombres con antecedentes prefirieron mayores pérdidas que las mujeres, sin embargo, con la probabilidad justo lo contrario. Estos datos son compatibles con una mayor evitación de consecuencias aversivas inmediatas por parte de hombres con antecedentes de violencia, lo que indica un mayor nivel de impulsividad.

Palabras clave: violencia doméstica; descuento intertemporal; impulsividad.

A violência é considerada hoje um fenômeno mundial, repercutindo em diferentes esferas, com discursos que abarcam questões políticas, filosóficas, psicológicas, sociológicas, antropológicas, religiosas e políticas. $\mathrm{O}$ tema da violência abarca questões históricas perpetuadas há muitas gerações, compreendendo grave e complexo problema com grande impacto social (Minayo, 2003).

A Organização Mundial de Saúde (OMS, 2002) define violência como o uso de força física ou de poder, tanto em ameaças quanto em prática, contra si mesmo, 
contra outra pessoa ou contra algum grupo ou comunidade, podendo resultar em danos, como morte, lesão, dano psicológico, privação ou desenvolvimento. Essa definição contempla uma gama de resultados que levam a questionamentos quanto aos impactos da violência, ressaltando que esta não necessariamente envolve dor ou morte, mas impacta significativamente pessoas, famílias, comunidades e sistema público de saúde.

Dentre os estudos sobre violência, destaca-se a violência contra a mulher, por envolver atos repetitivos que tendem a se ampliar tanto em frequência quanto em intensidade, contemplando coerção, humilhação, desqualificação, ameaças, agressões sexuais e físicas. Dessa forma, a violência contra a mulher é definida pela ONU (1992) como qualquer ato de violência baseado na diferença de gênero, que resulte em sofrimentos e danos físicos, sexuais e psicológicos da mulher, inclusive ameaças de tais atos, coerção e privação da liberdade, na vida pública ou privada. Para efeitos da Lei ${ }^{\circ}$ 11.340 de 2006, "configura violência doméstica e familiar contra a mulher qualquer ação ou omissão baseada no gênero que lhe cause morte, lesão, sofrimento físico, sexual ou psicológico e dano moral ou patrimonial". A lei consolida definições e direcionamentos de combate e punição do agressor (Brasil, 2006).

Skinner (2003) propõe como unidade de análise para o estudo do comportamento a contingência de três termos, em que a emissão de uma resposta (R) em uma situação ou ocasião ( $\mathrm{S}^{\mathrm{D}}$ - estímulo discriminativo) possui consequência que, por sua vez, altera a probabilidade futura dessa resposta voltar a ocorrer. Quando consequências aumentam a probabilidade futura dessa resposta, diz-se que essa resposta foi reforçada, e quando consequências diminuem a probabilidade da resposta, a resposta foi punida.

As noções de contingência e de controle do comportamento são aplicadas a situações sociais. A exposição a contingências nessas situações envolve "o comportamento de duas ou mais pessoas, uma em relação a outra ou em conjunto em relação ao ambiente comum" (Skinner, 2003, p. 325). Nesse caso, o reforço social implica a referência a outro organismo e a situação envolve o controle mútuo do comportamento. Ainda conforme Skinner (2003):

"O reforço social varia de momento para momento dependendo da condição do agente reforçador. Dessa forma, respostas diferentes podem conseguir o mesmo efeito, e uma resposta pode conseguir diferentes efeitos, dependendo da ocasião. Como resultado, o comportamento social e mais extenso que o comportamento comparável em ambiente não social. Também é mais flexível, no sentido de que o organismo pode mudar mais prontamente de uma resposta para outra quando o comportamento não for eficaz" (p. 327).

Muitas vezes, o controle exercido no ambiente social se baseia em consequenciar o comportamento do outro indivíduo via estimulação aversiva. Quando outros indivíduos ou as agências de controle estabelecem esses padrões de interação, visando, muitas vezes, reduzir comportamentos, geram certos subprodutos que não trazem vantagens para o controlador e são prejudiciais para o indivíduo e para o grupo, como fuga, revolta, resistência passiva e outros atos de violência.

Dessa forma, a violência tem sido relacionada no Behaviorismo Radical e na Análise do Comportamento a controle aversivo, notadamente o uso da punição. Skinner (1991) indica que, em contingências aversivas, os subprodutos são denominados no cotidiano como raiva, frustração, ansiedade, medo e agressão. Diferentemente, contingências reforçadoras estabelecem respostas de alegria, satisfação, felicidade. Além disso, enquanto as contingências aversivas envolvem coerção, nas contingências reforçadoras é estabelecido um "sentimento de liberdade".

Ao abordar o ciclo da violência doméstica, observa-se a relação do comportamento violento com as relações sociais e as práticas culturais (Gomes \& Costa, 2014). Assim, ao olhar a violência se está falando do comportamento humano, das relações entre as pessoas, questões que têm sido explicadas pela Análise do Comportamento (Sidman, 2009; Skinner, 2003) e especificamente análise da violência (Rachlin, 2004). Guerin e Ortolan (2017) descreveram, em termos operantes, os principais padrões envolvidos na violência doméstica. De acordo com a análise desses autores, cinco padrões funcionalmente relacionados podem ser descritos na violência contra a mulher: ações físicas diretas e ameaças; manipulação do contexto para controlar o comportamento da parceira; estratégias para manter segredo sobre o relacionamento, estratégias de monitoramento ou descoberta das atividades e contatos sociais da parceira; verbalizações para ameaçar ou convencer a mulher para adotar a visão de mundo do parceiro. Análise semelhante foi realizada por Pereira, Camargo e Aoyama (2018).

De acordo com Pierce e Cheney (2004), as contingências de agressão explicam abusos envolvendo crianças, esposas e outros grupos que podem apresentar certo grau de dependência da benevolência dos pais, maridos, entre outros. Em um exemplo apresentado por esses autores, tem-se uma mulher desempregada, com poucos amigos e casada com um homem que a agride. Quando esse marido fica agressivo, poucos recursos além da submissão fazem parte de seu repertório e ela pode ter aprendido que seu marido apenas ficaria com mais raiva. Por essas razões, o comportamento agressivo do marido pode acabar sendo modelado a níveis mais extremos. Além disso, em certas situações, a vítima desenvolve uma ligação emocional à pessoa que lhe trata mal, e esse comportamento pode passar a fazer parte do episódio agressivo, reforçando-o negativamente quando o ataque é reduzido ou removido pelos sinais de afeto da vítima. Com a repetição desse ciclo, as vítimas podem até alegar amar seus abusadores. 
Myers (1995) propôs um modelo baseado na contingência de três termos para descrever como a violência física pode controlar o comportamento da vítima. De acordo com ele, uma mulher com padrões assertivos e outros comportamentos que promovem a independência pode ser punida pela agressão física e verbal do parceiro. Em decorrência disso, a mulher pode obedecer a solicitações futuras do marido como meio de evitar ou fugir de ataques. Essa obediência pode reforçar o comportamento violento do marido, que pode fortalecer as agressões futuras. Esses reforçadores potenciais combinados podem aumentar a probabilidade de ação fisicamente agressiva do companheiro no futuro. Adicionalmente, o agressor raramente entra em contato com consequências punitivas, como sanções legais que podem reduzir o comportamento agressivo, enquanto a mídia e os pares modelam consequências da agressão relacionadas a padrões culturais e crenças, que acabam tendo função de manter a violência.

De acordo com Bell e Naugle (2005), as vítimas que contatam a polícia durante uma briga doméstica ou deixam a relação abusiva por breve período são mais suscetíveis ao risco de voltar à relação e manter a continuidade do abuso. Além disso, a decisão de se manter na relação abusiva é influenciada por diversos fatores, como o tempo de vínculo, o compromisso e o engajamento com o relacionamento interpessoal, variáveis com maior predição desse comportamento de submissão. Para entender de forma funcional essa relação, os autores propõem a aplicação da análise do comportamento. Segundo eles, conceituar a violência conjugal a partir da análise do comportamento tem como vantagens o fato dela poder se mostrar útil na identificação de variáveis centrais e relações funcionais entre variáveis relacionadas à violência. Assim, pode fornecer um modelo parcimonioso que una fatores identificados por outras teorias. Além disso, pode prover procedimentos científicos para mensurar os comportamentos a partir de modelos derivados de pesquisas de laboratório, contribuindo para a avaliação e fornecendo dados importantes para intervenções nesses contextos.

A análise proposta por Bell e Naugle (2005) para avaliar casos de violência a partir das noções analítico-comportamentais, estende a proposta de Myers (1995). Identifica princípios que podem contribuir para a compreensão da decisão pela permanência na relação abusiva, conforme exemplos específicos listados a seguir.

- Reforço positivo: elogios fornecidos à vítima por amigos e familiares pelo retorno ao agressor.

- Reforço negativo: a vítima evita abuso físico ao ligar para a polícia e deixar a relação.

- Punição: a vítima é punida ao sair do relacionamento por encontrar barreiras para alternativas de vida.

- Extinção: a vítima continua a ser abusada mesmo após abandonar a relação, e esse comportamento entra em extinção.
- Déficits comportamentais: a vítima tem poucas habilidades para alternativas de vida.

- Comportamento governado por regras: vítimas que têm crenças como "se eu trabalhar a relação, meu parceiro vai mudar" tendem a se manter mais na relação.

- Escolha e economia comportamental: a vítima permanece no relacionamento quando há oferta de mais incentivos (lar, suporte social e emocional, intimidade sexual, estabilidade financeira) do que em outras alternativas.

- Desconto intertemporal: vítima escolhe reforçadores mais imediatos associados à permanência na relação do que os reforçadores atrasados derivados da saída do relacionamento.

Uma das variáveis envolvidas nesse processo é o autocontrole. Skinner (2003), ao utilizar o termo autocontrole, refere-se às modificações realizadas pelo próprio indivíduo em seu ambiente a fim de controlar melhor seu próprio comportamento, em uma relação na qual uma resposta controladora altera a probabilidade de ocorrência de uma segunda resposta, chamada de resposta controlada. Essas modificações podem ocorrer de diferentes formas: restrição física e ajuda física; mudança de estímulo; privação e saciação; manipulação de condições emocionais; uso de estimulação aversiva; drogas; condicionamento operante; punição.

Ao tentar captar a noção de Skinner (2003), Rachlin (1970) se propôs a estudar autocontrole experimentalmente, definindo-o como um tipo de comportamento de escolha que pode ser controlado por duas variáveis determinantes: atraso e magnitude do reforço. Ao descrever autocontrole e impulsividade, Rachlin (1970) destaca que ambos são comportamentos que envolvem conflitos entre magnitude, atraso, qualidade e frequência do reforço, além de outros fatores. Em sua operacionalização inicial, propõe um modelo de escolha no qual relaciona impulsividade com a escolha de um reforçador imediato de menor magnitude e autocontrole com a escolha do reforço com maior atraso e maior magnitude (Hanna \& Todorov, 2002; Rachlin \& Green, 1972).

O paradigma de Rachlin demonstra o quanto a preferência por alternativas de autocontrole ou de impulsividade pode ser influenciada por fatores ambientais, ampliando assim sua utilidade na avaliação de comportamentos a partir de uma perspectiva comportamental (Hanna \& Todorov, 2002; Logue, 1988). Apesar disso, esses autores consideram que o modelo proposto por Rachlin restringe-se apenas a uma das formas de autocontrole propostas por Skinner.

Desde 1991, pesquisadores têm desenvolvido e testado um modelo de avaliação de preferência em relação às consequências atrasadas e prováveis, como meio de analisar autocontrole a partir da preferência relacionada à perda do valor de consequências atrasadas ou prováveis (Myerson \& Green, 1995; Rachlin, Raineri, \& Cross, 
1991). O modelo básico desenvolvido por Rachlin consiste na apresentação de alternativas de escolha sucessivas em que uma alternativa permanece com uma quantia maior e mais atrasada (ou menos provável) e a outra alternativa apresenta valores menores certos e imediatos. A mudança da preferência entre a quantia atrasada ou provável e a quantia imediata possibilita mensurarmos o valor subjetivo da quantia maior e a preferência pela alternativa de autocontrole ou de impulsividade. Com isso, a preferência entre quantias certas/imediatas e quantias atrasadas/prováveis têm sido utilizadas como indicativos do nível de autocontrole/impulsividade (Coelho, Hanna, \& Todorov, 2003).

Outra técnica utilizada programa duas alternativas fixas que diferem quanto à magnitude e atraso ou probabilidade, e tem como medida a preferência por uma alternativa no longo prazo. Se a preferência for pela alternativa de maior atraso com mais ganhos, ela é descrita como autocontrolada. Se o indivíduo prefere a alternativa de menor atraso com menor ganho, descreve-se essa escolha como impulsiva (Cherek, Moeller, Dougherty, \& Rhoades, 1997).

Os dados produzidos nessa linha investigativa têm correlacionado impulsividade e comportamentos socialmente relevantes, como abuso de drogas, tabagismo e violência. Cherek et al. (1997) submeteram indivíduos em liberdade condicional, com e sem histórico de violência, a atrasos fixos para consequências mais imediatas e atrasos variáveis para consequências maiores e mais atrasadas. A medida utilizada foi a porcentagem de escolhas da alternativa com maior atraso e os dados mostraram maior porcentagem de escolhas por essa alternativa pelos participantes sem histórico de violência.

Considerando as relações entre agressividade e o uso de drogas, Allen, Moeller, Rhoades e Cherek (1998) investigaram a existência de relação entre impulsividade e histórico de uso de drogas ao comparar 32 usuários e 26 não usuários em um procedimento de escolha semelhante ao de Cherek et al. (1997). O atraso médio com o qual os participantes usuários ficaram indiferentes à consequência menor mais imediata foi significativamente menor que dos não usuários, sugerindo maior nível de impulsividade dentro de uma perspectiva de desconto intertemporal.

Cherek et al. (2007) mostraram a relação entre impulsividade e violência a partir do paradigma de autocontrole de Rachlin (1970) e, analogamente, Bell e Naugle (2005) sugerem que a relação de violência doméstica envolve, dentre outras variáveis, o conflito entre as consequências imediatas de permanecer na relação e as consequências atrasadas de abandonar a relação, caracterizadas por maior magnitude. Apesar dos dados sugerirem uma relação entre o histórico de violência e a preferência por recompensas mais imediatas ou mais garantidas ou entre perdas mais atrasadas ou menos prováveis, nenhum estudo investigou essas relações diretamente na comparação de casais com e sem histórico de violência doméstica. Mais especificamente, não há dados comparando relações entre impulsividade e violência doméstica na Análise do Comportamento.

Este trabalho busca fazer uma avaliação comportamental do autocontrole a partir da concepção de autocontrole como a preferência por recompensas maiores mais atrasadas ou prováveis, de forma que valores maiores indicam maior nível de autocontrole (Myerson \& Green, 1995; Rachlin et al., 1991). Nessas avaliações, um mesmo indivíduo é avaliado em diferentes condições, comparando seu comportamento, o que pode também ser usado para análise em relação a indivíduos com outros repertórios ou históricos comportamentais, como tradicionalmente é realizado na análise do comportamento e na terapia comportamental. É comum a utilização de instrumentos psicológicos validados em associação com técnicas de observação ou instrumentos verbais que relatam frequência de comportamentos passados ou probabilidade de comportamentos futuros, possibilitando inferir as variáveis das quais o comportamento é função, como meio de possibilitar intervenções mais eficazes (Godoy, 1996; Oliveira, Noronha, Dantas, \& Santarém, 2005).

Frente ao panorama descrito, esse estudo se propõe a avaliar o padrão de autocontrole do agressor e de mulheres agredidas, comparando-os com os padrões de homens e mulheres sem histórico de agressão. Mais especificamente, visa a avaliação de padrões de escolha com perda de dinheiro e prisão atrasadas ou prováveis, comparando respostas de homens agressores e mulheres agredidas com e sem histórico de violência.

\section{Método}

\section{Participantes}

Participaram do presente estudo 82 mulheres e 53 homens, recrutados em uma delegacia de atendimento à mulher e uma instituição de ensino superior do estado de Goiás. Os participantes foram divididos em dois grupos: com histórico de violência (G1), ou seja, que apresentaram relatos de situações abusivas no relacionamento, independentemente de terem ou não denúncia formal, e sem histórico de violência (G2), e cada um dos grupos foi subdividido em homens (masc) e mulheres (fem). Dos subgrupos sem histórico, o G1_masc contou com 35 participantes com idades de 20 e 68 anos $(M=39,14$ anos, $D P=12,51)$ e o G1_fem foi composto por 35 mulheres com idades de 20 a 65 anos $(M=36,57$ anos, $D P=11,00)$. Os subgrupos com histórico foram compostos por 18 homens (G2_masc), com idades de 20 a 49 anos $(M=31,83$ anos, $D P=7,77)$ e por 47 mulheres, 16 a 59 anos $(M=32,78$ anos, $D P=10,05)$.

\section{Instrumentos}

O experimento utilizou o software Alternativas 1.0, elaborado pelos pesquisadores Cristiano Coelho e 
Nicolau Chaud de Castro Quinta especialmente para esta pesquisa, com o objetivo de analisar atraso e probabilidade tanto em contexto de escolha monetária, quanto em contexto de escolha envolvendo dias na prisão. $\mathrm{O}$ software, construído em plataforma Delphi 5, possibilita a configuração de diferentes contextos hipotéticos de ganho ou perda prováveis ou atrasados, dispostos em pares de escolhas apresentados em cartões na tela do computador, expostos lado a lado. Os textos referentes a cada situação de perda de dinheiro foram apresentados na tela do computador em letra Trebuchet MS, tamanho 16. Diferentes protocolos com pares de cartões são configurados de forma que em cada conjunto uma alternativa permanece fixa e a outra tem tempos ou probabilidades apresentadas em ordem crescente ou decrescente. Ao final de cada coleta o software gera um arquivo com todas as escolhas em formato .TXT.

A coleta de dados foi realizada em dois lugares: em salas da clínica de atendimento psicológico no CESUC (Centro de Ensino Superior de Catalão - GO) e em uma sala na Delegacia Especializada em atendimento à Mulher (DEAM) de Catalão (GO).

\section{Procedimentos}

O estudo caracteriza-se como uma pesquisa com delineamento experimental com tratamento intersujeitos. Ele compõe um projeto de pesquisa maior, que foi submetido ao CONEP com o CAAE 84991718.2.0000.0037 e obteve sua aprovação com o parecer 2576567. Após a aprovação pelo comitê de ética, os examinadores realizaram a seleção dos participantes junto à DEAM e na faculdade, cumprindo os requisitos éticos. Durante o convite, leram o Termo de Consentimento Livre e Esclarecido (TCLE), e os que aceitaram participar foram submetidos aos procedimentos após a assinatura do TCLE.

Antes de apresentar as alternativas para o voluntário do estudo, uma tela inicial de configuração deveria ser preenchida pelo examinador. A tela de configuração permitia registrar o nome do participante, idade, escolaridade, o nome do examinador, bem como configurações da sessão, como intervalo entre tentativas, tempo de bloqueio de escolha, critério de mudança, enunciado de escolhas e sequências da sessão. Após o lançamento das informações e da seleção das sequências, a coleta de dados era iniciada com a instrução a ser seguida pelo participante, podendo variar de acordo com o sexo e o grupo em que o participante estava inserido.

Os participantes tinham que realizar escolhas entre consequências aversivas certas e imediatas e consequências aversivas atrasadas ou prováveis. Duas condições ficaram em vigor: tempos hipotéticos na prisão e perda hipotética de quantias de dinheiro. Com tempos na prisão e escolhas com atraso havia tempo fixo menor de um mês ou seis meses para prisão imediata e, em diferentes escolhas, tempos de prisão maiores daqui a um ano. Com tempo na prisão e escolhas probabilísticas, as alternativas apresentavam a certeza de ficar preso por um tempo fixo, um mês ou seis meses, a partir de agora ou $50 \%$ de chance de ficar preso imediatamente por períodos maiores. Os tempos de prisão atrasados ou prováveis eram aumentados a cada escolha para dois, três, quatro e cinco meses (em referência a um mês de prisão certa ou imediata) e, para um ano, um ano e meio, dois anos e dois anos e meio (com referência a seis meses de prisão certa ou imediata). Ao início da tarefa com probabilidade e atraso, tanto para as mulheres quanto para os homens, eram apresentadas as seguintes instruções, independentemente de terem ou não histórico de violência. As partes entre parênteses indicam alterações nas instruções apresentadas para homens e mulheres:

O objetivo desta pesquisa é analisar a escolha em situações que envolvem tempo na prisão. Suponha que você e seu marido (sua esposa) se envolveram em uma situação de agressão e, em decorrência, você (ela) fez uma denúncia na delegacia. Você poderá escolher como prefere que ele cumpra a pena referente a tal agressão, considerando as alternativas que serão apresentadas.

$\mathrm{Na}$ tela aparecerão duas alternativas ao mesmo tempo e você deverá com o ponteiro do mouse clicar em cima de uma delas, indicando sua escolha. Assim que o fizer, outra situação hipotética aparecerá e o mesmo deverá ser feito até o procedimento ser encerrado.

Após as instruções, os participantes eram confrontados com telas apresentadas sequencialmente. Cada tela apresentava duas alternativas em que uma alternativa permanecia fixa e a outra apresentava tempo crescente de prisão. Dessa forma, nas escolhas com um mês de prisão, os participantes dos grupos de homens deveriam indicar se preferiam "Ficar preso por um mês a partir de agora" ou "Ficar preso por um mês (dois meses, três meses, quatro meses, cinco meses, seis meses) daqui a um ano", no caso de atraso, e "Ter $50 \%$ de chance de ficar preso por um mês (dois meses, três meses, quatro meses, cinco meses, seis meses) a partir de agora". O mesmo procedimento foi aplicado com seis meses de prisão, com as durações de prisão atrasada de um ano, um ano e seis meses, dois anos e dois anos e seis meses. Para as participantes dos grupos de mulheres, as alternativas questionavam sobre a preferência de seu marido ficar preso imediatamente ou conforme o atraso ou probabilidade expressa, no caso de violência hipotética.

$\mathrm{Na}$ condição com quantias de dinheiro apresentadas na situação de atraso, os participantes escolhiam entre uma perda imediata de $\mathrm{R} \$ 100,00$ ou perdas maiores daqui a um ano. Na situação de probabilidade, as escolhas eram entre uma perda certa de $\mathrm{R} \$ 100,00$ agora ou $50 \%$ de chance de perder um valor maior agora. Os valores maiores atrasados ou prováveis utilizados foram de $\mathrm{R} \$ 200,00$, $\mathrm{R} \$ 300,00, \mathrm{R} \$ 400,00$ e $\mathrm{R} \$ 500,00$. A instrução apresentada ao início das escolhas com quantias de dinheiro, igual para homens e mulheres, foram as seguintes: 
O objetivo desta pesquisa é analisar a situação de escolha em situações que envolvem perda de dinheiro. Suponha que você irá perder uma quantia de dinheiro. Você pode escolher quando prefere perdê-la, levando em consideração as alternativas que serão apresentadas.

$\mathrm{Na}$ tela aparecerão duas alternativas ao mesmo tempo e você deverá, com o ponteiro do mouse, clicar em cima de uma delas, indicando sua escolha. Assim que o fizer, outra situação hipotética aparecerá e o mesmo deverá ser feito até que o procedimento seja encerrado.

Após as instruções, os participantes foram submetidos a escolhas sequenciais, com alternativas que indicavam uma perda imediata de $\mathrm{R} \$ 100,00$ ou perdas maiores em um ano ou com $50 \%$ de chance. Cada tela apresentava duas alternativas: uma alternativa permanecia fixa e a outra apresentava perdas crescentes. Nas escolhas com atraso, os participantes dos grupos de homens e dos grupos de mulheres deveriam indicar se preferiam "Perder $\mathrm{R} \$ 100,00$ agora" ou "Perder (R $\$ 200,00, \mathrm{R} \$ 300,00, \mathrm{R} \$ 400,00$, $\mathrm{R} \$ 500,00)$ daqui a um ano", no caso de atraso e "Ter $50 \%$ de chance de perder ( $\mathrm{R} \$ 200,00, \mathrm{R} \$ 300,00, \mathrm{R} \$ 400,00$, $\mathrm{R} \$ 500,00)$ a partir de agora”, com probabilidade.

Todos os participantes realizaram escolhas com atraso e probabilidade, tanto com os tempos de prisão imediatos e certos de um mês e seis meses, quanto com perda de quantias de dinheiro. As ordens de exposição foram variadas. Metade dos participantes iniciou a tarefa com tempo na prisão e metade com perda de quantias de dinheiro. Em cada contexto, metade iniciou com atraso e metade com probabilidade. No contexto de tempo na prisão, metade foi submetido inicialmente ao tempo de um mês e metade inicialmente com seis meses.

\section{Análise de Dados}

Os dados foram organizados em planilhas com todas as escolhas dos voluntários nos diferentes contextos. Para análise das escolhas, tomou-se o tempo da prisão ou a quantia, em que mudasse da alternativa provável/ atrasada para imediata/certa à medida que o tempo na prisão ou a quantia aumentava, conforme a condição. No caso de preferência exclusiva pela certa imediata, utilizou-se a média entre zero e a menor quantia ou o menor tempo de prisão. No caso de preferência exclusiva pela atrasada provável, considerou-se a mudança na próxima quantia ou tempo na prisão que seria apresentado conforme o aumento programado. As principais medidas derivadas dessa análise foram o tempo de prisão atrasado ou provável equivalente ao tempo de prisão imediato e certo, respectivamente. A utilização de duas durações visou avaliar os possíveis efeitos da magnitude do tempo da prisão. Para possibilitar as análises comparativas nos contextos com prisões de um mês e de seis meses, as durações de prisão obtidas com seis meses foram transformadas em medidas relativas, dividindo-se o valor obtido por seis.

Com o objetivo de avaliar os valores de equivalência relativos aplicou-se o Teste de Mann Whitney U para todas as comparações entre todos os grupos. Tomou-se como critério um nível de significância de 0,05 .

\section{Resultados}

A Figura 1 apresenta os tempos de prisão atrasados equivalentes a um mês e seis meses de prisão imediata para todos os grupos.

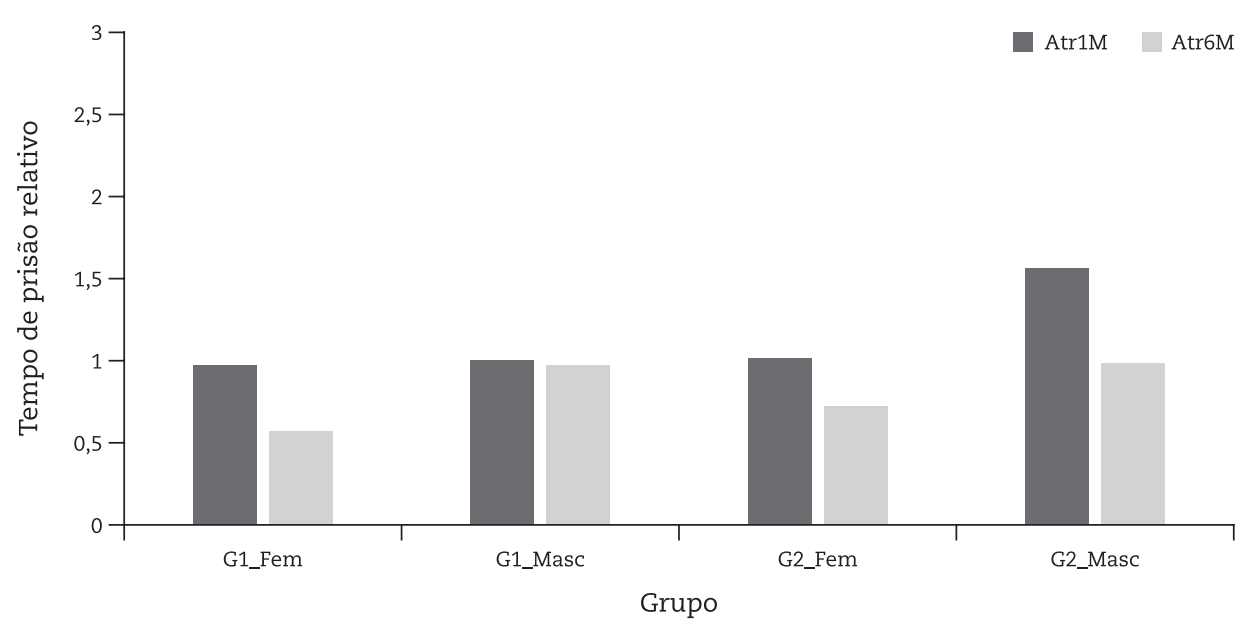

Figura 1. Tempo equivalente de prisão relativo nas condições com atraso para prisão por um mês (Atr1M) e seis meses (Atr6M) para os Grupos sem histórico (G1) e com histórico (G2) de violência 
Observa-se que homens e mulheres sem histórico de violência e mulheres com histórico de violência estimaram tempos relativos de prisão semelhantes para a condição de um mês. Esse valor ficou abaixo do obtido para os homens com histórico de violência. Esses dados indicam preferência por tempo de prisão mais imediato para os três primeiros grupos e preferência por tempo maior de prisão atrasado para os homens com histórico de violência.

Para os seis meses de prisão, os tempos relativos para as mulheres sem histórico e com histórico de violência ficaram abaixo de um, o que significa preferência por tempo menor que os seis meses, mas com prisão imediata. Os dados dos homens dos dois grupos indicaram indiferença entre seis meses de prisão imediatos e seis meses de prisão em um ano. Comparando-se as duas durações de tempo na prisão, notou-se que três subgrupos (mulheres sem histórico e com histórico de violência e homens com histórico de violência) apresentaram durações relativas menores com seis meses que as apresentadas com um mês de prisão.

A análise realizada a seguir focalizou a situação com $50 \%$ de chance de ficar preso por um mês ou seis meses a partir de agora. Esses dados estão apresentados na Figura 2.

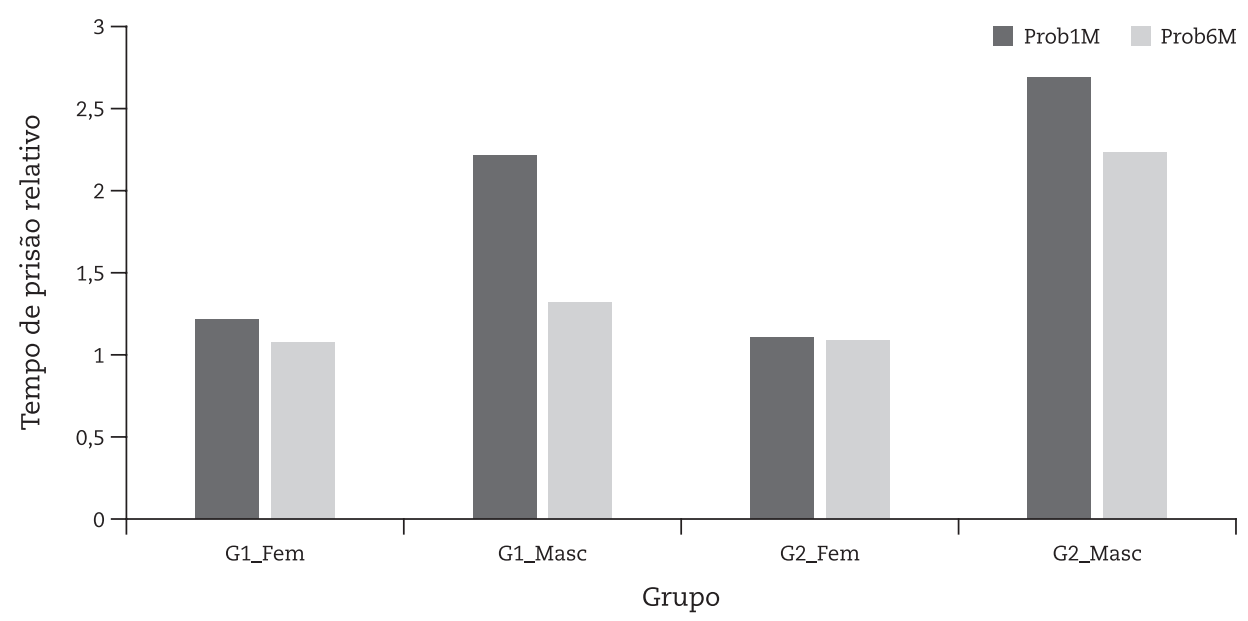

Figura 2. Tempo equivalente de prisão relativo nas condições com probabilidade para prisão por um mês (Prob1M) e seis meses (Prob6M) para os Grupos sem histórico (G1) e com histórico (G2) de violência

As participantes dos grupos sem histórico e com histórico de violência apresentaram tempos relativos de prisão para seus esposos próximos ao tempo de prisão provável, tanto com um mês quanto com seis meses de prisão. Os participantes dos subgrupos homens sem histórico e com histórico de violência indicaram, em média, um período de prisão de 2,21 meses e 2,67 meses na situação com um mês de prisão, respectivamente. $\mathrm{Na}$ situação com seis meses com $50 \%$ de chance, os tempos médios foram de 1,31 meses para o grupo sem histórico e 2,22 vezes maior que os seis meses com prisão certa, sugerindo preferência pela alternativa provável, nos dois casos. Comparando os grupos, as médias do tempo de prisão das participantes com e sem histórico foram menores que dos parceiros, com maiores diferenças entre as mulheres com histórico de violência e os homens com histórico de violência.

Os dados das escolhas com perda de quantias de dinheiro são apresentados na Figura 3. Na parte superior, encontram-se as médias dos valores dos $\mathrm{R} \$ 100,00$ atrasados e, na parte inferior, as médias dessa quantia com probabilidade de perda.

Com atraso, as médias ficaram acima de $\mathrm{R} \$ 100,00$ para todos os grupos, variando de $\mathrm{R} \$ 122,86$ para as mulheres sem histórico a $\mathrm{R} \$ 194,12$ para homens com histórico de violência. Os grupos de homens sem histórico e mulheres com histórico apresentaram valores intermediários e semelhantes entre si. Na situação com probabilidade, as médias dos grupos mulheres sem histórico, homens sem histórico e mulheres com histórico de violência aproximaram-se dos $\mathrm{R} \$ 200,00$, que corresponde ao valor esperado da quantia de $\mathrm{R} \$ 100,00$ a ser perdida com $50 \%$ de chance. Já a média do grupo com histórico de violência foi de $\mathrm{R} \$ 182,35$, abaixo do valor esperado e que indica preferência pela alternativa de impulsividade.

Os valores de $\mathrm{Z}$ e da probabilidade obtidos a partir da aplicação do teste Mann Whitney U nas comparações entre os valores subjetivos de tempo na prisão e perda de dinheiro estão mostrados na Tabela 1. 

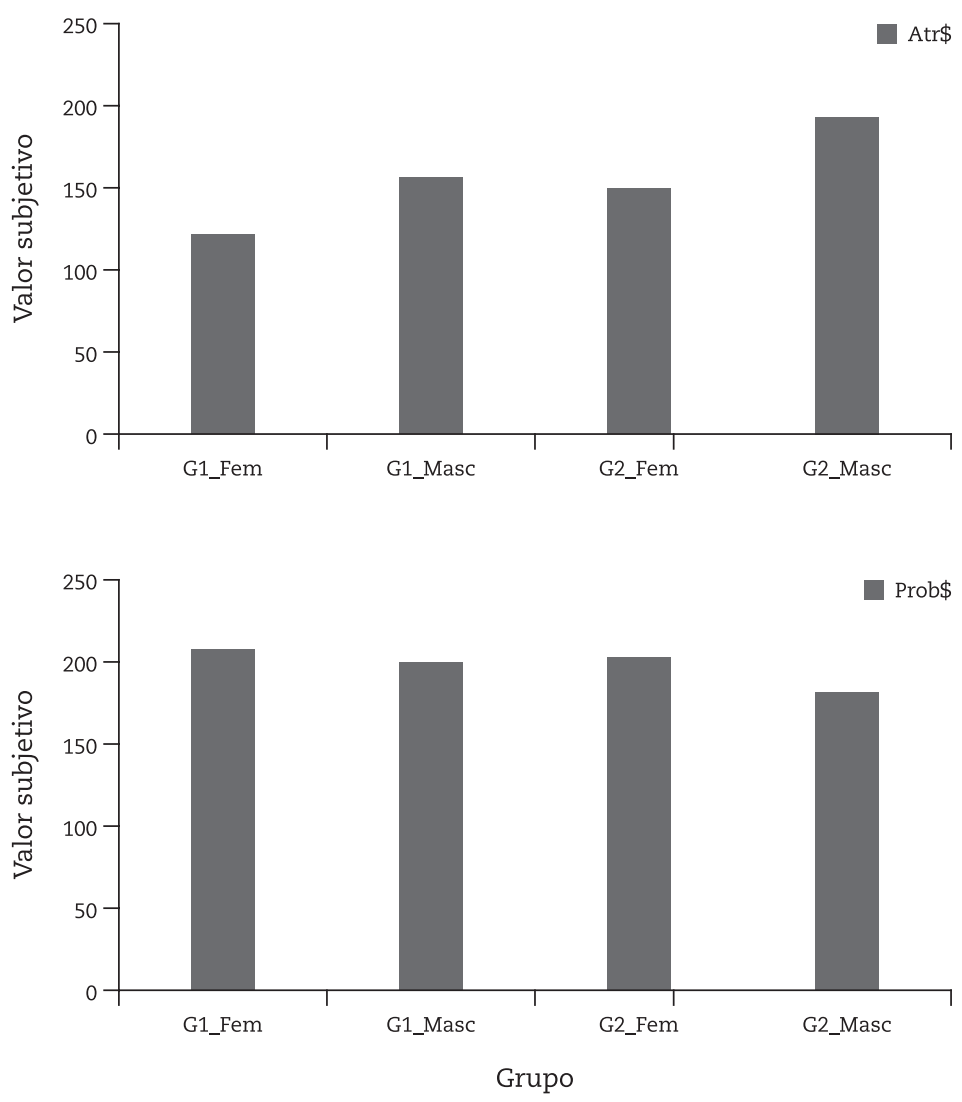

Figura 3. Quantia equivalente aos $\mathrm{R} \$ 100,00$ nas situações de atraso (Gráfico superior) e probabilidade (Gráfico inferior) para os Grupos sem histórico (G1) e com histórico (G2) de violência

Tabela 1

Valores de Z e Nível de Significância das Comparações Estatísticas dos Valores de Equivalência dos Diferentes Grupos

\begin{tabular}{lcccccc}
\hline \multicolumn{1}{c}{ Comparações } & Atr1M & Atr6M & Atr\$ & Prob1M & Prob6M & Prob\$ \\
\hline Hs-Hc & $0,72(0,235)$ & $-0,13(0,452)$ & $-1,34(0,090)$ & $-0,68(0,248)$ & $-1,88(0,030)^{*}$ & $0,49(0,312)$ \\
Ms-Mc & $-0,52(0,301)$ & $-0,19(0,424)$ & $0,47(0,319)$ & $-1,46(0,072)$ & $-0,67(0,251)$ & $-0,87(0,192)$ \\
Hs x Ms & $0,14(0,444)$ & $1,25(0,105)$ & $0,29(0,385)$ & $2,49(0,006)^{*}$ & $-0,40(0,341)$ & $-0,21(0,417)$ \\
Hc x Mc & $-1,27(0,102)$ & $-1,29(0,098)$ & $-1,41(0,079)$ & $-3,45(0,000)^{* *}$ & $-2,28(0,011)^{*}$ & $0,11(0,456)$ \\
\hline
\end{tabular}

Nota. ${ }^{*} p<0,05 ;{ }^{* *} p<0,01$. H=Homens; M=Mulheres; $s=$ sem histórico de violência; $c=c o m$ histórico de violência; Atr=atraso; Prob=probabilidade; $1 \mathrm{M}=$ tempo de prisão fixo de 1 mês; $6 \mathrm{M}$ =tempo de prisão fixo de 6 meses; $\$=$ contexto de perda de dinheiro

Diferenças estatisticamente significativas nos valores de equivalência entre prisão ou perda de dinheiro certas e imediatas e as durações de prisão e perda de dinheiro atrasados ou prováveis foram observadas com tempo de prisão de um mês na situação de probabilidade entre homens e mulheres sem histórico de violência $(Z=2,49, p=0,006)$ e entre homens com histórico de violência e mulheres com histórico de violência $(Z=-3,45, p \leq 0,001)$. Para probabilidade com seis meses de tempo de prisão, foram encontradas diferenças significativas entre homens sem e com histórico de violência $(Z=-1,88, p=0,030)$ e entre homens e mulheres com histórico de violência $(Z=-2,28, p=0,011)$. Para as situações com atraso e com quantias de dinheiro, os dados dos grupos não diferiram significativamente.

\section{Discussão}

Os dados referentes às escolhas de tempo na prisão com atraso que mostraram tempos na prisão menores para as participantes mulheres com e sem histórico de violência e para os homens sem histórico de violência, com tempos relativos de prisão ainda menores para as mulheres, indicam preferência por consequência mais 
imediata para si (no caso dos homens sem histórico) ou para o parceiro (no caso das mulheres com e sem histórico de violência). Por outro lado, os homens com histórico de violência apresentaram tempos médios de prisão maiores na situação de um mês, indicando que preferem uma prisão maior futura a uma prisão menor mais imediata. Esses dados são consistentes com a literatura científica ao apontar que indivíduos com histórico de violência apresentam maior nível de impulsividade em situação de ganhos nas quais indivíduos em condicional preferiram ganhos mais imediatos (Cherek et al., 1997).

Quando uma situação de escolha envolve consequências reforçadoras, os indivíduos apresentam desconto em função do atraso ou da probabilidade. Esse efeito é diferencial quando se tem consequências de maior magnitude (Myerson, \& Green, 1995). No presente estudo, os tempos relativos de prisão, na situação de seis meses com atraso. foram menores que as observadas com um mês para três subgrupos: mulheres com e sem histórico, e homens com histórico de violência, sugerindo possível efeito da magnitude, no qual quantias maiores são descontadas diferentemente (Myerson, \& Green, 1995). Essa interpretação pode não ser plausível, visto que dados de outros estudos obtiveram menor taxa de desvalorização de quantias maiores. Além disso, em situações aversivas, como perda de dinheiro ou tempo na prisão (como no presente estudo) o efeito da magnitude não é sistematicamente observado (Ostaszewski \& Bialaszek, 2010). Porém, nas situações de probabilidade, dados semelhantes fortalecem a suposição acima, sugerindo a possibilidade de o efeito de magnitude ser observado no contexto de tempo na prisão. No entanto, os tempos médios de prisão sugeridos pelas mulheres foram próximos, independente do contexto, porém próximo aos respectivos tempos mínimos, um mês e seis meses. Para os homens dos dois grupos, o impacto de uma chance de $50 \%$ de ficar preso foi maior, principalmente para os com histórico de violência.

Tomando-se em conjunto esses dados, pode-se dizer que as mulheres foram mais avessas ao atraso e à probabilidade e os homens foram mais propensos a arriscar, mas não propensos a esperar. Esses dados podem ser interpretados ainda como diferenças nos controles das respostas das mulheres e homens avaliados. As questões apresentadas para as mulheres questionavam o tempo que o parceiro deveria ficar preso, supondo que elas foram agredidas. Já as questões apresentadas aos homens partiram da suposição de que ao agredirem as parceiras poderiam ficar presos (hoje ou daqui a um tempo, com atraso; hoje com certeza ou com uma probabilidade menor). Nesse sentido, as respostas das mulheres podem ser analisadas como reforçadas negativamente e, assim, a prisão mais imediata do agressor teria maior valor reforçador, o que é compatível com a proposta de Bell e Naugle (1995) da importância de se considerar o desconto intertemporal na violência doméstica. Porém, apesar de uma preferência pela prisão imediata e certa para o parceiro agressor, muitas variáveis acabam reduzindo a chance de uma denúncia, como o papel tradicional masculino e feminino, privacidade da relação, modelo de família intacta como o ideal, responsabilidade da vítima, ciúme relacionado ao amor, ciúme relacionado à violência, justificativa para a violência, dentre outras (Gomes \& Costa, 2014), para as quais avaliações sistemáticas devem ser realizadas para fornecer subsídios para políticas sociais.

Por outro lado, as respostas dos homens envolvem uma consequência aversiva para si mesmo, ou seja, pode ter função punitiva. Como o atraso impõe perda no valor dessa consequência, postergar a prisão é uma forma de minimizar essa aversividade, mesmo que apenas imediatamente. Junto a isso, o atraso para a prisão pode indicar a possibilidade da retirada da denúncia, bem como possibilitar ao agressor continuar a aplicar as estratégias que induzem à permanência das mulheres em uma relação violenta. Novos estudos podem investigar taxas de desconto expondo os participantes a escolhas com maior conjunto de variáveis, o que não foi desenvolvido no presente trabalho, em função de evitar a perda de participantes, considerando a população a qual pertencem.

Nas escolhas com dinheiro, a utilização de $\mathrm{R} \$ 100,00$ procurou basear-se em uma quantia que possivelmente fosse ecologicamente válida. Apesar de ter se baseado em dados demográficos oficiais, segundo os quais a maioria da população envolvida em violência doméstica pertence a classe média baixa, a maioria da amostra relatou renda próxima a $\mathrm{R} \$ 2.000,00$. Nessas escolhas, nas situações com atraso, os homens com histórico de violência preferiram, em média, perder quantias maiores atrasadas que as mulheres com e sem histórico de violência. Esse dado corrobora a suposição de que eles foram mais propensos à espera, dado este compatível com maior impulsividade, conforme mostrado por Cherek et al. (1997) e Allen et al. (1998). Contudo, o valor subjetivo médio do grupo de homens com histórico de violência na situação de probabilidade com quantia de dinheiro abaixo dos outros grupos aponta para um efeito diferencial de atraso e probabilidade, já descrito com ganho de quantias de dinheiro (Coelho et al., 2003).

Apesar da sistematicidade observada nas análises dos dados entre os grupos, com mulheres apresentando preferência pela prisão mais certa e imediata em relação aos homens com histórico de violência, as diferenças foram significativas em quatro comparações, todas envolvendo probabilidade de ficar preso. Mais que uma característica do fenômeno, é possível que esse dado represente a variabilidade da amostra em relação a diferentes padrões de desvalorização com quantias de dinheiro e com tempo na prisão. Um dos grandes pontos a se considerar no estudo do autocontrole é o fato de que indivíduos podem ser mais autocontrolados em um contexto e mais impulsivo em outros (Coelho et al., 2003). 
Conforme Bell e Naugle (2005), Guerin e Ortolan (2017) e Pereira et al. (2018), a violência doméstica é um fenômeno complexo e multidimensional. Ele afeta diferentes classes e envolve diferentes tipos de controle estabelecidos na relação interpessoal. Mesmo que esses autores tenham proposto um conjunto de princípios operantes para a análise desse fenômeno, dentre eles a existência de conflito entre consequências atrasadas e imediatas, isso não significa que esse conflito esteja presente em todas as situações. Porém, mesmo que esteja, é possível que as participantes do presente estudo não estejam sob controle dessas consequências. Um grupo foi composto por mulheres que, mesmo tendo apresentado denúncia, ainda não entraram em contato com as consequências atrasadas decorrentes do abandono da relação abusiva. Outro grupo foi composto por mulheres que não tiveram contato com as consequências aversivas imediatas de uma relação abusiva. De forma semelhante podemos estender essa apreciação para os grupos dos homens com e sem histórico de violência. Para que se possa investigar essa possibilidade, os participantes poderiam ser submetidos a uma nova aplicação, que permitisse comparar não só os casais com histórico e sem histórico, mas entre os casais com histórico de violência, aqueles que permaneceram fora da relação e os que retornaram para a relação abusiva, em um estudo longitudinal.

Em termos metodológicos, o estudo se constituiu como tentativa de examinar variações nas escolhas, utilizando-se um atraso básico e uma probabilidade, o que pode limitar análises acerca do efeito do atraso e da probabilidade sobre as escolhas de tempo na prisão e, consequentemente, sobre o desconto nessas situações. Estudos posteriores podem submeter indivíduos com histórico de violência a diferentes atrasos e probabilidades, permitindo o acesso à variação de respostas sob controle dessas variáveis, inclusive para avaliar modelos matemáticos aplicados a essas variações. Adicionalmente, podem ser desenvolvidas medidas para que os participantes relacionem a gravidade da violência cometida ou recebida e o tempo ou a chance de que essa violência venha a ser consequenciada com prisão ou outras medidas.

As diferenças entre a avaliação dos homens e mulheres sobre as consequências derivadas da violência doméstica foram mais claras em condições que envolveram probabilidade de ficar preso. Isto sugere a necessidade de maior investigação para prover dados que venham a contribuir com políticas públicas voltadas para esse fenômeno de supra relevância social.

\section{Referências}

Allen, T. J., Moeller, F. G., Rhoades, H. M., \& Cherek, D. R. (1998). Impulsivity and history of drug dependence. Drug and alcohol dependence, 50, 137-145. doi:10.1016/S0376-8716(98)00023-4

Bell, K. M., \& Naugle, A. E. (2005). Understanding stay/leave decisions in violent relationships: A behavior analytic approach. Behavior and Social Issues, 14, 21-45. doi: 10.5210/bsi.v14i1.119

Brasil (2006). Lei 11.340, de 7 de agosto de 2006. Diário Oficial da União. Brasília, 8 agosto de 2006. Recuperado de http://www.planalto. gov.br/CCIVIL/ Ato2004-2006/2006/Lei/L11340.htm

Cherek, D. R., Moeller, F. G., Dougherty, D. M., \& Rhoades, H. (1997). Studies of violent and nonviolent male parolees: II. Laboratory and psychometric measurements of impulsivity. Biological Psychiatry, 41, 523-529. doi: 10.1016/S0006-3223(96)00426-X

Coelho, C., Hanna, E. S., \& Todorov, J. C. (2003). Magnitude, atraso e probabilidade de reforço em situações hipotéticas de risco. Psicologia: Teoria e Pesquisa, 19, 269-278. doi: 10.1590/S0102-37722003000300009

Gomes, H. C. D. R., \& Costa, N. (2014). Violência contra a mulher: Uma pesquisa empírica sobre regras descritivas comuns na sociedade ocidental. Acta Comportamentalia, 22(1), 89-100. Recuperado de https://www.redalyc.org/pdf/2745/274530012007.pdf

Godoy, A. (1996). O processo de avaliação comportamental. In: Caballo, V. E. (Org.). Manual de técnicas de terapia e modificação do comportamento (pp. 99-108). São Paulo: Santos.

Guerin, B., \& Ortolan, M. (2017). Analyzing domestic violence Behaviors in their contexts: Violence as a Continuation of social strategies by other means. Behavior and Social Issues, 26, 5-26. doi: 10.5210/bsi.v26i0.6804

Hanna, E. S., \& Todorov, J. C. (2002). Modelos de autocontrole na Análise Experimental do Comportamento: Utilidade e crítica. Psicologia: Teoria e Pesquisa, 18, 337-343. doi: 10.1590/S0102-37722002000300014

Logue, A. W. (1988). Research on self-control: An integrating framework. Behavioral and Brain Sciences, 11, 665-679. doi: 10.1017/ S0140525X00053978

Minayo, M. C. S. (2003). A violência dramatiza causas. Em M. C. S. Minayo \& E. Souza. (Org.) Violência sob o olhar da saúde: A infrapolítica da contemporaneidade brasileira. Rio de Janeiro: Fiocruz, 2003 (pp. 23-47).

Myers, D. L. (1995). Eliminating the battering of women by men: Some considerations for behavior analysis. Journal of Applied Behavior Analysis, 28, 493-507. doi: 10.1901/jaba.1995.28-493

Myerson, J., \& Green, L. (1995). Discounting of delayed rewards: Models of individual choice. Journal of the Experimental Analysis of Behavior, 64(3), 263-276. doi: 10.1901/jeab.1995.64-263

Oliveira, K. L., Noronha, A. P. P., Dantas, M. A., \& Santarem, E. M. (2005). O psicólogo comportamental e o uso de instrumentos psicológicos. Psicologia em Estudo (Maringá), 10, 127-135. doi: 10.1590/S1413-73722005000100015

Organização Mundial da Saúde (OMS) (2002). Oficina regional para las Américas. Informe mundial sobre la violência y la salud. Washington.

Organização das Nações Unidas (ONU). (1992). Conselho social e econômico. Relatório do trabalho de grupo na violência contra a mulher. Viena: Nações Unidas. 
Ostaszewski, P., \& Bialaszek, W. (2010). Probabilistic discounting in "certain gain-uncertain loss" and "certain loss-uncertain gain" conditions. Behavioural processes, 83(3), 344-348. doi: 10.1016/j.beproc.2010.01.006

Pereira, D. C. S., Camargo, V. S., \& Aoyama, P. C. N. (2018). Análise funcional da permanência das mulheres nos relacionamentos abusivos: Um estudo prático. Revista Brasileira de Terapia Comportamental e Cognitiva, 20, 9-25. doi: 10.31505/rbtcc.v20i2.1026

Pierce, W., \& Cheney, D. (2004). Behavior Analysis and Learning. New Jersey: Laurence Erlbaum Associates.

Rachlin, H. (1970). Modern behaviorism. San Francisco: Freeman.

Rachlin, H. (2004). The behavioral economics of violence. Annals of the New York Academy of Science, 1036, 325-335. doi: 10.1196/ annals.1330.020.

Rachlin, H., \& Green, L. (1972). Commitment, choice and self-control. Journal of the Experimental Analysis of Behavior, 17(1), 15-22. doi: 10.1901/jeab.1972.17-15

Rachlin, H., Raineri, A., \& Cross, D. (1991). Subjective probability and delay. Journal of the Experimental Analysis of Behavior, 51, 233-244. doi: 10.1901/jeab.1991.55-233

Sidman, M. (2009). Coerção e suas implicações. (M. A. Andery, \& T. M. Sério, Trans.) Campinas, SP: Livro Pleno.

Skinner, B. F. (1991). Questões recentes na análise do comportamento. São Paulo: Papirus.

Skinner, B. F. (2003). Ciência e comportamento humano (11 a ed.). São Paulo: Martins.

\section{Sobre os autores}

Cristiano Coelho é Doutor em Psicologia. Professor Adjunto da Escola de Ciências da Saúde da PUC Goiás.

Renata Limongi França Coelho Silva é psicóloga do Instituto Integrado de Saúde e Comportamento, Catalão-GO. 